\title{
Effect of Acetylcholine on Vascular Capacity in the Dog
}

\author{
Edward W. Supple and WM. John Powell, JR., The Cardiac Unit, Department of \\ Medicine, Massachusetts General Hospital, and Department of Medicine, \\ Harvard Medical School, Boston, Massachusetts 02114
}

\begin{abstract}
A B S T R A C T Acetylcholine produces venoconstriction of isolated vein strip preparations. However, the effect of acetylcholine on overall vascular capacity is not known. To investigate this effect and to elucidate the mechanisms involved, 38 anesthetized dogs were placed on total cardiopulmonary bypass, splenectomized, and given intraarterial infusions of acetylcholine. Almost all of the effect on vascular volume was found to be in the splanchnic circulation, because in four eviscerated animals there was no significant change in capacity. In the animals in which the mesenteric arteries were cannulated to provide constant inflow, and the hepatic vein was cannulated to measure splanchnic venous outflow, acetylcholine infusion for 5 and $21 \mathrm{~min}$ increased splanchnic vascular capacity in all animals by $107 \pm 28$ (SEM) $\mathrm{ml}$ $(P<0.01)$ and $291 \pm 132 \mathrm{ml}(P<0.05)$, respectively. This increase in splanchnic vascular volume was associated with a rapid and sustained increase in transhepatic resistance to portal blood flow for the duration of the infusions $(P<0.01)$. In the animals in which the portal vein was vented proximal to the liver, no significant volume change occurred in the splanchnic vasculature with acetylcholine infusion. Increasing hepatic venous pressure to elevate portal venous pressure to the same level as that achieved with acetylcholine resulted in a similar increase in splanchnic vascular volume. Atropine, but not adrenergic blockade, blocked the acetylcholine-induced volume retention, indicating that the effect of acetylcholine was direct. Substantial volume retention was also achieved by stimulation of the distal ends of the sectioned cervical vagi. Thus, acetylcholine administration directly increases transhepatic resistance and is associated with a pooling of volume in the splanchnic vasculature that would, in the intact animal, result in a decrease in venous return to the heart.
\end{abstract}

Address reprint requests to Dr. Powell at Massachusetts General Hospital.

Received for publication 16 February 1981 and in revised form 13 March 1981.

\section{INTRODUCTION}

The innervation of blood vessels and in particular the autonomic control of vascular capacity is thought to be sympathetic in origin (1). To date, the parasympathetic nervous system has been considered to exert its influence on the cardiovascular system primarily through its effect on heart rate and contractility $(2,3)$. There has been little investigation on the possible effects of cholinergic stimulation on vascular capacity. The effect of vagal activity on the splanchnic viscera has been well documented and is known to be important in regulating intestinal motility and secretion by the stomach (4) and pancreas (5). Parasympathetic fibers travel alongside the arterial vessels of the splanchnic viscera (6). Furthermore, Sutherland (7) has demonstrated that parasympathetic ganglia are present in the walls of the portal vein and the hepatic vasculature, including the hepatic veins. From the above, it is apparent that there is an anatomic basis for vagal control of splanchnic vascular capacity.

Evidence to date suggests that the splanchnic vasculature is a potentially important blood reservoir in the intact organism. This area has been shown to contain $\sim 20-30 \%$ of total blood volume (8), and under conditions of severe hypotension, it is capable of mobilizing two-thirds of its blood volume content (9). It has been recently demonstrated that beta adrenergic receptor stimulation with isoproterenol administration is capable of a central displacement of blood through decreasing splanchnic blood volume (10). It is possible that cholinergic stimulation might result in substantial pooling of blood within the splanchnic vasculature. However, diffuse venoconstriction is produced by acetylcholine in isolated vein strip preparations (11) which ought to augment, rather than decrease, venous return to the heart.

Our study was undertaken to examine the pharmacologic effect of acetylcholine on vascular capacity. Particular attention was directed toward the splanchnic vasculature under conditions of controlled hemodynamics in order to assess the effect of acetylcholine on 
splanchnic vascular volume and to elucidate the mechanism of its action.

\section{METHODS}

43 adult mongrel dogs of either sex weighing between 18 and $25 \mathrm{~kg}$ were anesthetized with chloralose $(90 \mathrm{mg} / \mathrm{kg}$ i.v.) and urethane $(900 \mathrm{mg} / \mathrm{kg}$. i.v.). After endotracheal intubation, ventilation was accomplished with a Bird Mark 7 constant pressure respirator (Bird International Sales Corporation, Palm Springs, Calif.) with $100 \%$ oxygen. A right lateral thoracotomy and a midline abdominal incision were performed. A total cardiopulmonary bypass preparation with an isolated splanchnic vascular system, as illustrated schematically in Fig. 1, was used.

After the administration of heparin $(3 \mathrm{mg} / \mathrm{kg}$ i.v. $)$, the femoral veins and superior vena cava were cannulated, and the azygos vein was ligated. The venous blood from these veins was directed, via an overflow column, the height of which was set to produce a venous pressure of $8 \mathrm{~cm} \mathrm{H}_{2} \mathrm{O}$, to a Harvey bubble oxygenator (model H-1000, C. R. Bard International, Inc., Murray Hill, N. J.) and heat exchanger ( $37^{\circ}$ $\left.\pm 0.5^{\circ} \mathrm{C}\right)$ and returned through a variable speed-calibrated roller pump (A in Fig. 1) (Cardiovascular Instruments, Wakefield, Mass.) to the femoral arteries. To exclude the pulmonary, bronchial, and coronary circulation, the aorta $(2 \mathrm{~cm}$ above the aortic valve) and the pulmonary hila were crossclamped. Drains were placed in the right and left ventricular cavities to assure adequacy of cross-clamping. The rate of pumping into the femoral arteries was maintained constant throughout each experiment.

The splanchnic vascular system was then isolated from the remainder of the systemic vasculature. The inferior vena cava was ligated just below the liver. The inferior vena cava was also cannulated in the chest in retrograde fashion to drain the hepatic venous outflow, which was directed through an overflow column, the height of which was set at $8 \mathrm{~cm} \mathrm{H}_{2} \mathrm{O}$. The hepatic venous blood was then returned to the oxygenator. In an attempt to have the model more closely simulate the human vascular system, splenectomy was performed to eliminate the possible influence of the muscular capsule of the dog spleen on vascular capacity. Next, the cranial and caudal mesenteric arteries and the celiac axis, which was ligated adjacent to the aorta, were isolated and perfused by the variable speed-calibrated roller pump labeled B in Fig. 1. Splanchnic arterial inflow was maintained constant throughout each experiment.

The oxygenator was calibrated with a scale of $20-\mathrm{ml}$ increments (from 0 to $3,000 \mathrm{ml}$ ) before each experiment, so that the reciprocal of changes in oxygenator volume could be observed as changes in total vascular capacity. Hepatic vein flows of 30-s duration were manually collected in graduated cylinders. Changes in splanchnic vascular capacity were determined by integrating the difference between the mean hepatic vein flow of the control period and the observed flows during and following each intervention. Peripheral systemic vascular capacity was determined from the difference between the total and the splanchnic vascular capacities.

In two animals, the hepatic artery was cannulated and

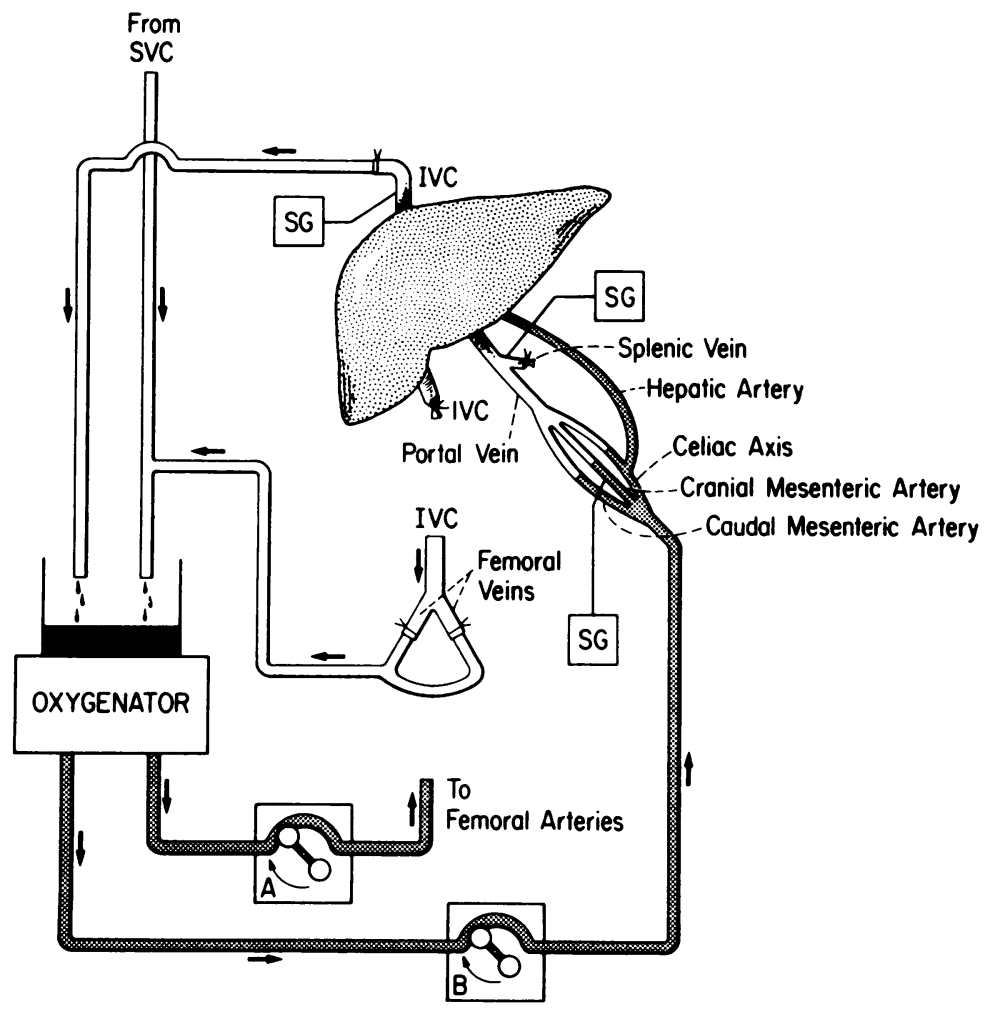

FIGURE 1 The experimental preparation. See text for details. SVC, superior vena cava; IVC, inferior vena cava; SG, strain gauge. 
separately perfused at a constant flow rate to eliminate any possible arterial redistribution of blood flow between the hepatic and mesenteric circulations.

To investigate the effects of cholinergic stimulation on the portal venous system alone, we cannulated the portal vein in seven animals just proximal to its bifurcation at the porta hepatis and ligated the distal portal vein at the bifurcation. The portal venous outflow to the oxygenator was directed via an overflow column to maintain portal venous pressure nearly constant. The hepatic artery was ligated at the porta hepatis.

In each of four animals the hepatic venous overflow column was raised to match the increase in portal pressure obtained during a previous 5 -min acetylcholine infusion. After $5 \mathrm{~min}$, the column was lowered to its initial level.

To examine the effects of acetylcholine on the peripheral vasculature directly, the drug was infused into the femoral arteries in four animals after evisceration. In these animals, the entire splanchnic viscera including the liver, stomach, and intestines had been removed.

All pressures were measured with Statham P23Db transducers (Statham Instruments, Inc., Oxnard, Calif.); the frequency response of the pressure measurement system was linear up to $30 \mathrm{cps}$. Systemic and splanchnic arterial pressures were measured through a short cannula placed in the left brachial artery and in a branch of the cranial mesenteric artery in the intestinal arcade, respectively. Portal vein pressure was measured from a cannula inserted into a branch of the splenic vein and advanced into the portal vein. Hepatic vein wedge pressure was determined in three animals by a 7 Swan-Ganz catheter (Edwards Laboratories, Santa Ana, Calif.), which was advanced in retrograde fashion through the hepatic vein into the liver. Hepatic vein and central venous pressures were measured at the bases of their respective overflow columns. Intestinal lumen pressure was measured by placing in the duodenum an elongated latex balloon containing saline. All measured pressures were recorded on a Hewlett-Packard 7700 eight-channel recorder (HewlettPackard, Co., Waltham, Mass.). Transhepatic resistance was calculated from the difference between portal vein pressure and hepatic vein pressure divided by the hepatic vein flow.

In eight animals, 5-min acetylcholine (anhydrous acetylcholine chloride, Sigma Chemical Co., St. Louis, Mo.) infusions $(2 \mathrm{mg} / \mathrm{min}$ in normal saline with $0.5 \%$ mannitol at a concentration of $2 \mathrm{mg} / \mathrm{ml}$ ), and in 15 animals, 21-min infusions into the splanchnic arterial system just proximal to the trifurcation were performed (Fig. 1). The infusions were administered at $2 \mathrm{ml} / \mathrm{min}$ with a parenteral Fluid Delivery System (model i.v. 5000, Valleylab, Boulder, Col.). The initial hepatic vein flows during each infusion were purposely diverted for the first $75 \mathrm{~s}$ of each infusion to prevent possible systemic effects of recirculating acetylcholine during this period.

To eliminate all visible shunts from the portal to the splanchnic circulation, in the eight animals in which the 5min acetylcholine infusions were administered, running sutures were placed in the esophagus and rectum, and the inferior mediastinum was divided. Blood flow through the diaphragm was eliminated by clamping the circumference of the diaphragm with multiple Kelly clamps. In one of these animals, silastic (Canton Biomedical Products, Inc., Boulder, Col.) was infused into the splanchnic arterial system at the conclusion of the experiment to document the lack of visible communication between the portal and systemic circulations. In this animal, the silastic perfused to, but not beyond, the points of occlusion.

In three animals, $20 \mathrm{mg}$ atropine (Dosette, Elkins-Sinn, Inc., Cherry Hill, N. J.) was administered to 4 liters of extracorporeal blood volume over $5 \mathrm{~min}$. Both before and after atropine blockade, $6 \mu \mathrm{g}$ isoproterenol (Isuprel, Winthrop Laboratories, New York) injected into the mesenteric artery was associated with the same decrease in pressure of $15 \mathrm{~mm}$ $\mathrm{Hg}$. $400 \mu \mathrm{g}$ methoxamine (Vasoxyl, Burroughs Wellcome Co., Research Triangle Park, N. C.) injected into the mesenteric artery before and after atropine caused arterial pressure to increase by $50 \mathrm{~mm} \mathrm{Hg}$. Thus, the vasculature was still responsive after atropine.

In nine animals, either phenoxybenzamine (100-300 mg; Dibenzyline, Smith Kline \& French Laboratories, Philadelphia, Pa.) propranolol (100-200 mg; Inderal, Ayerst Laboratories, New York), or both were administered into the oxygenator to achieve adrenergic blockade. After alpha adrenergic receptor blockade, no response to an intraarterial injection of $100 \mu \mathrm{g}$ phenylephrine (Neosynephrine, Winthrop Laboratories) was observed. After beta receptor blockade, the response to $6 \mu \mathrm{g}$ isoproterenol was abolished.

In five animals cervical vagectomy was performed and the distal ends of the sectioned vagus nerves were stimulated bilaterally with a Grass SDS stimulator (Grass Instrument Co., Quincy, Mass.) at $2 \mathrm{cps}, 20 \mathrm{~V}$, and $20 \mathrm{~ms}$. To insure that the nervous system to the intestines and liver remained intact, the splanchnic arterial system was not cannulated in these experiments. In two additional animals, cervical vagectomy was performed and $20 \mathrm{mg}$ Atropine blockade was administered to the blood volume in the reservoir before bilateral distal stimulation of the sectioned vagus nerves. In these animals, the vasculature was still responsive as demonstrated by increases in arterial pressure of $30 \mathrm{~mm} \mathrm{Hg}$ in response to $300 \mu \mathrm{g}$ Methoxamine and decreases in arterial pressure of $10 \mathrm{~mm} \mathrm{Hg}$ in response to $4 \mu \mathrm{g}$ isoproterenol.

A double-tailed paired Student's $t$ test was used for all statistical analyses except those involving transhepatic resistance. Since the distribution of estimates of transhepatic resistance was nonhomogeneous, the Wilcoxon (12) signed rank test was used to determine the statistical analysis of the resistance data. Significance in all cases was assumed only with $P<0.05$.

\section{RESULTS}

Figs. 2A and $\mathrm{B}$ show the mean hemodynamic data obtained in the animals in which 5-min infusions of acetylcholine were administered. In the top panel of Fig. 2A, splanchnic vascular volume, following an initial transient decrease, progressively increased. At the end of the 5-min infusion there was a volume gain of $107 \pm 28 \mathrm{ml}(\mathrm{SEM})(P<0.01)$. Following termination of the infusion (i.e., the postcontrol period), the slope of the gain in splanchnic vascular volume plateaued and then returned slightly toward control. In two of eight animals, splanchnic volume returned to control levels, four of eight returned toward control levels, and two of eight continued to increase. Transhepatic resistance substantially increased in value within the first minute following the onset of infusion, remained elevated $\left(40 \pm 10 \mathrm{~cm} \mathrm{H}_{2} \mathrm{O} /\right.$ liter per min $)(P<0.01)$ from a control of $25 \pm 7 \mathrm{~cm} \mathrm{H}_{2} \mathrm{O} /$ /liter per min throughout the infusion, and returned toward the control level after the infusion. The increase in total vascular volume in the third panel paralleled the gain in splanchnic vascular volume, and at the end of the acetylcholine infusion a gain of $84 \pm 28 \mathrm{ml}(P<0.05)$ was observed. 

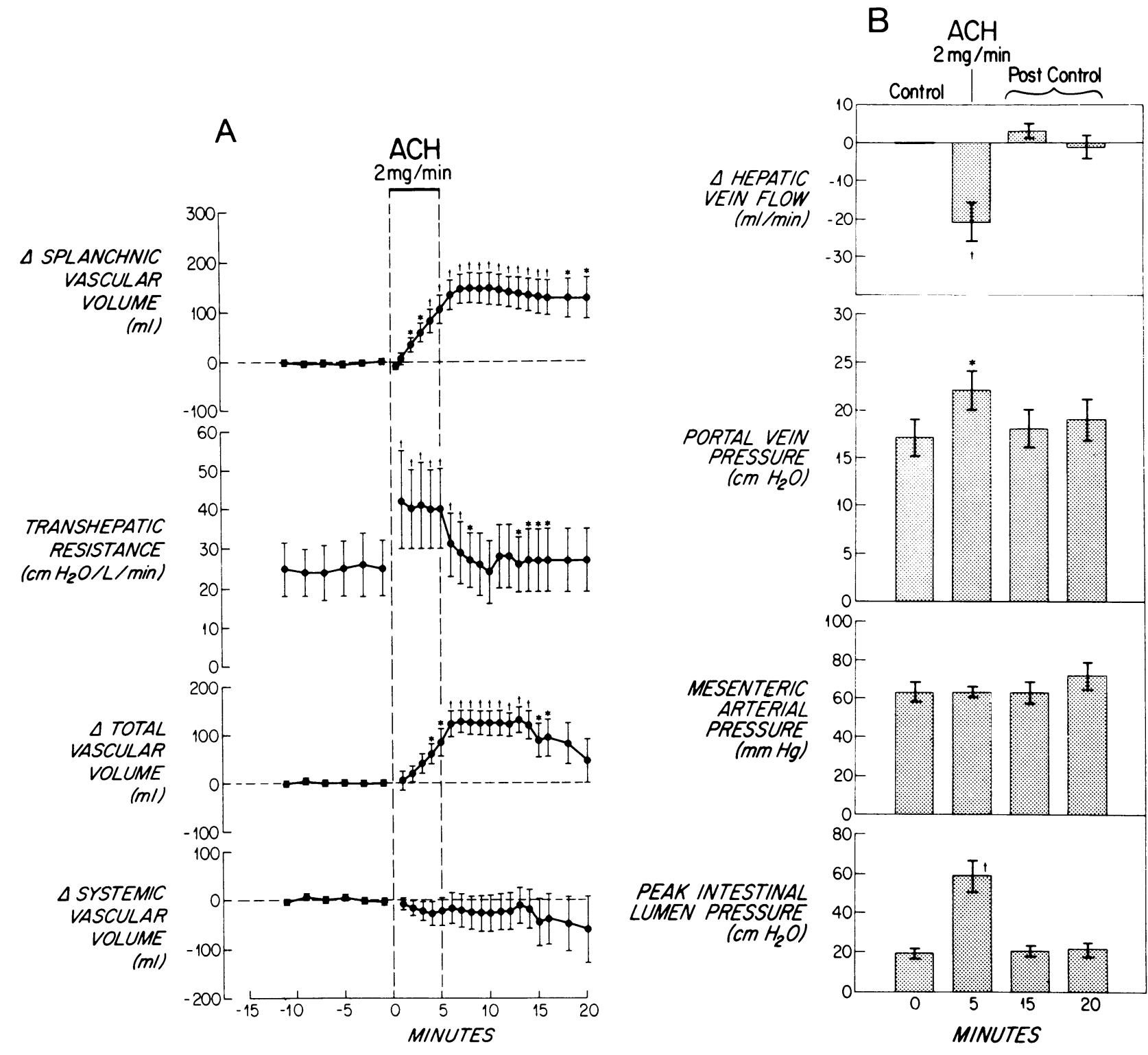

Figure 2 Mean data on the effects of 5-min intraarterial infusions of acetylcholine in eight animals. (A) Note that the increase in splanchnic vascular volume associated with the elevation of transhepatic vascular resistance is similar to the increase in total vascular volume. (B) Note the significant decrease in hepatic vein flow at the end of $5 \mathrm{~min}$ of acetylcholine $(\mathrm{ACH})$ administration which was associated with a significant change in mean mesenteric arterial pressure. ${ }^{*} P<0.05$; $+P<0.01 ; n=8$.

There was no significant difference between the gain in splanchnic volume and the gain in total vascular volume. Although mean systemic vascular volume decreased slightly during acetylcholine administration, this change was not significant. The top panel of Fig. $2 \mathrm{~B}$ shows the mean decrease in hepatic vein flow of $21 \pm 5$ $\mathrm{ml} / \mathrm{min}(P<0.01)$ from the control flow of $430 \pm 42 \mathrm{ml} /$ $\min$. The cumulative effect of this decrease in flow corresponded to the observed increase in splanchnic vas- cular volume (top panel of Fig. 2A). Hepatic vein flow increased slightly following cessation of the infusion and returned to the control level by $20 \mathrm{~min}$. For splanchnic vascular volume to have returned to control levels following the infusion of acetylcholine, hepatic venous outflow would have had to increase to levels substantially greater than those of the control period. Mean portal vein pressure increased significantly during the infusion of acetylcholine and returned 
TABLE I

Effect of Intraarterial Acetylcholine Infusions under Conditions of Constant Hepatic Arterial Flow

\begin{tabular}{|c|c|c|c|c|}
\hline & \multirow[b]{2}{*}{ Control } & \multirow{2}{*}{$\begin{array}{c}\begin{array}{c}\text { Acetylcholine } \\
(2 \mathrm{mg} / \mathrm{min})\end{array} \\
5 \mathrm{~min}\end{array}$} & \multicolumn{2}{|c|}{ Postcontrol } \\
\hline & & & $15 \mathrm{~min}$ & $20 \mathrm{~min}$ \\
\hline$\Delta$ Splanchnic vascular volume, $m l$ & - & $\begin{array}{l}113 \\
126\end{array}$ & $\begin{array}{l}151 \\
202\end{array}$ & $\begin{array}{l}160 \\
232\end{array}$ \\
\hline Transhepatic resistance, $\mathrm{cm} \mathrm{H}_{2} \mathrm{O} /$ liter/min & $\begin{array}{l}10.4 \\
13.9\end{array}$ & $\begin{array}{l}19.9 \\
25.0\end{array}$ & $\begin{array}{l}10.4 \\
16.1\end{array}$ & $\begin{array}{l}10.4 \\
16.1\end{array}$ \\
\hline Portal vein pressure, $\mathrm{cm} \mathrm{H}_{2} \mathrm{O}$ & $\begin{array}{l}12 \\
12\end{array}$ & $\begin{array}{l}15.3 \\
14\end{array}$ & $\begin{array}{l}12 \\
12.5\end{array}$ & $\begin{array}{l}12 \\
12.5\end{array}$ \\
\hline Hepatic vein flow, $\mathrm{ml} / \mathrm{min}$ & $\begin{array}{l}448 \\
320\end{array}$ & $\begin{array}{l}428 \\
292\end{array}$ & $\begin{array}{l}448 \\
312\end{array}$ & $\begin{array}{l}448 \\
312\end{array}$ \\
\hline Mean mesenteric arterial pressure, $\mathrm{mm} \mathrm{Hg}$ & $\begin{array}{l}57 \\
65\end{array}$ & $\begin{array}{l}55 \\
65\end{array}$ & $\begin{array}{l}52 \\
65\end{array}$ & $\begin{array}{l}55 \\
65\end{array}$ \\
\hline Mean hepatic arterial pressure, $m \boldsymbol{m ~} \mathbf{H g}$ & $\begin{array}{l}70 \\
65\end{array}$ & $\begin{array}{l}67 \\
65\end{array}$ & $\begin{array}{l}70 \\
65\end{array}$ & $\begin{array}{l}72 \\
65\end{array}$ \\
\hline
\end{tabular}

The top and bottom number of each pair indicate the results from each of two animals. Note that splanchnic vascular volume increased in both animals and that this increase was associated with an elevation of transhepatic resistance.

toward control levels in the postcontrol period. In the third panel of Fig. 2B, it can be seen that there was no significant change in mesenteric arterial pressure, which at a constant inflow reflected mesenteric arterial resistance: in three of eight animals mesenteric arterial resistance increased, in four of eight animals it decreased, and in one of eight animals there was no change in response to acetylcholine. There was also no significant change in mean systemic arterial pressure from the control of $64 \pm 7 \mathrm{~mm} \mathrm{Hg}$. Peak intestinal lumen pressure, as seen in the bottom panel of Fig. 2B, increased significantly above control during acetylcholine administration. With infusion of the vehicle of saline and $0.5 \%$ mannitol at $2 \mathrm{ml} / \mathrm{min}$ in two animals, there was no change in any of the above hemodynamics.

In the 15 animals that did not have collaterals ligated and that received longer infusions of acetylcholine, similar changes in splanchnic vascular volume, transhepatic resistance, hepatic vein flow, portal vein pressure, and total vascular volume occurred at the end of 5 min of infusion. These changes were sustained throughout the period of infusion. The gain in splanchnic vascular volume at $5 \mathrm{~min}$ was $90 \pm 33 \mathrm{ml}$ $(P<0.05)$. This was slightly but not significantly less than in the animals with the collaterals ligated. At the end of the 21-min infusion, the splanchnic vascular volume gain was $291 \pm 132 \mathrm{ml}(P<0.05)$. This was not significantly greater than the increase of $192 \pm 88 \mathrm{ml}$ in total vascular volume at $21 \mathrm{~min}$ of infusion.

In the two animals in which hepatic arterial inflow was maintained constant before, during, and after 5-min infusions of acetylcholine, results similar to those obtained in the experiments in which the hepatic artery was not separately cannulated were seen (Table I). Of interest was the lack of change in either hepatic arterial or mesenteric arterial pressure.

\section{EVISCERATED ANIMALS}

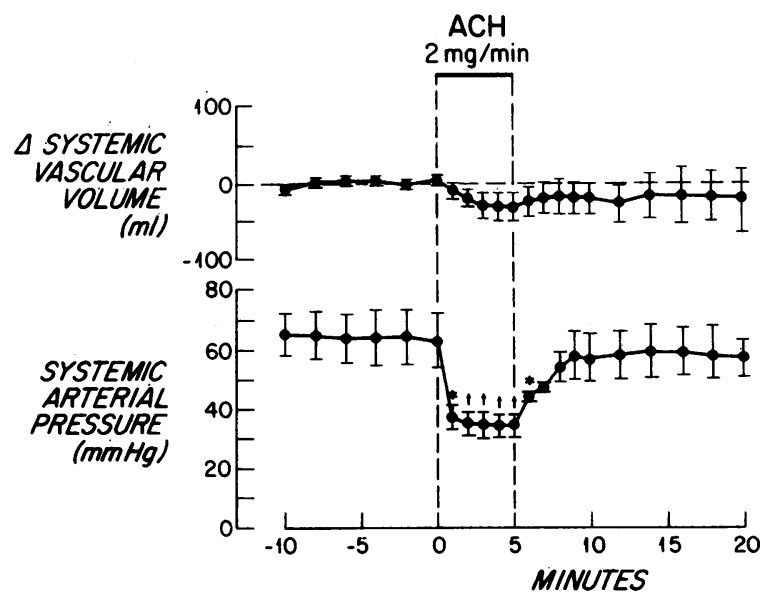

FIGURE 3 The effect of intraarterially administered acetylcholine (ACH) on systemic vascular volume and mean systemic arterial pressure in four eviscerated animals. Note the lack of significant change in systemic vascular volume. $* P<0.05 ;+P<0.01 ; n=4$. 
In the four eviscerated animals there was a greater direct delivery of acetylcholine to the periphery than occurred in the noneviscerated animals and systemic arterial pressure decreased significantly (Fig. 3). In spite of the greater delivery of acetylcholine, little change in vascular volume resulted $(-32 \pm 18 \mathrm{ml}, \mathrm{NS})$ indicating that the predominant effect of acetylcholine on the total vascular capacity appears to be in the splanchnic vasculature.

In the seven animals in which the portal vein was vented proximal to liver to investigate the effect of acetylcholine directly on the portal venous system, there was an insignificant decrease of $50 \pm 68 \mathrm{ml}$ in volume at $21 \mathrm{~min}$ (top panel of Fig. 4). Portal pressure remained at nearly constant levels throughout these experiments (second panel). There was no significant change in total and systemic vascular volume in response to acetylcholine.

In an animal with the portal circulation to the liver intact (Fig. 5), it can be seen that regardless of whether portal pressure was increased by acetylcholine or by mechanical elevation of hepatic vein pressure, similar increases in splanchnic vascular capacity were observed after $5 \mathrm{~min}$. In each of four animals that underwent the same experimental protocol, similar data were obtained. In response to acetylcholine infusion, the portal vein pressure increase of $3.1 \pm 1 \mathrm{~cm} \mathrm{H}_{2} \mathrm{O}$ from a control level of $12.8 \pm 1 \mathrm{~cm} \mathrm{H}_{2} \mathrm{O}$ was associated with a gain in splanchnic volume of $104 \pm 7 \mathrm{ml}$. Elevation of the hepatic vein pressure resulted in an increase of

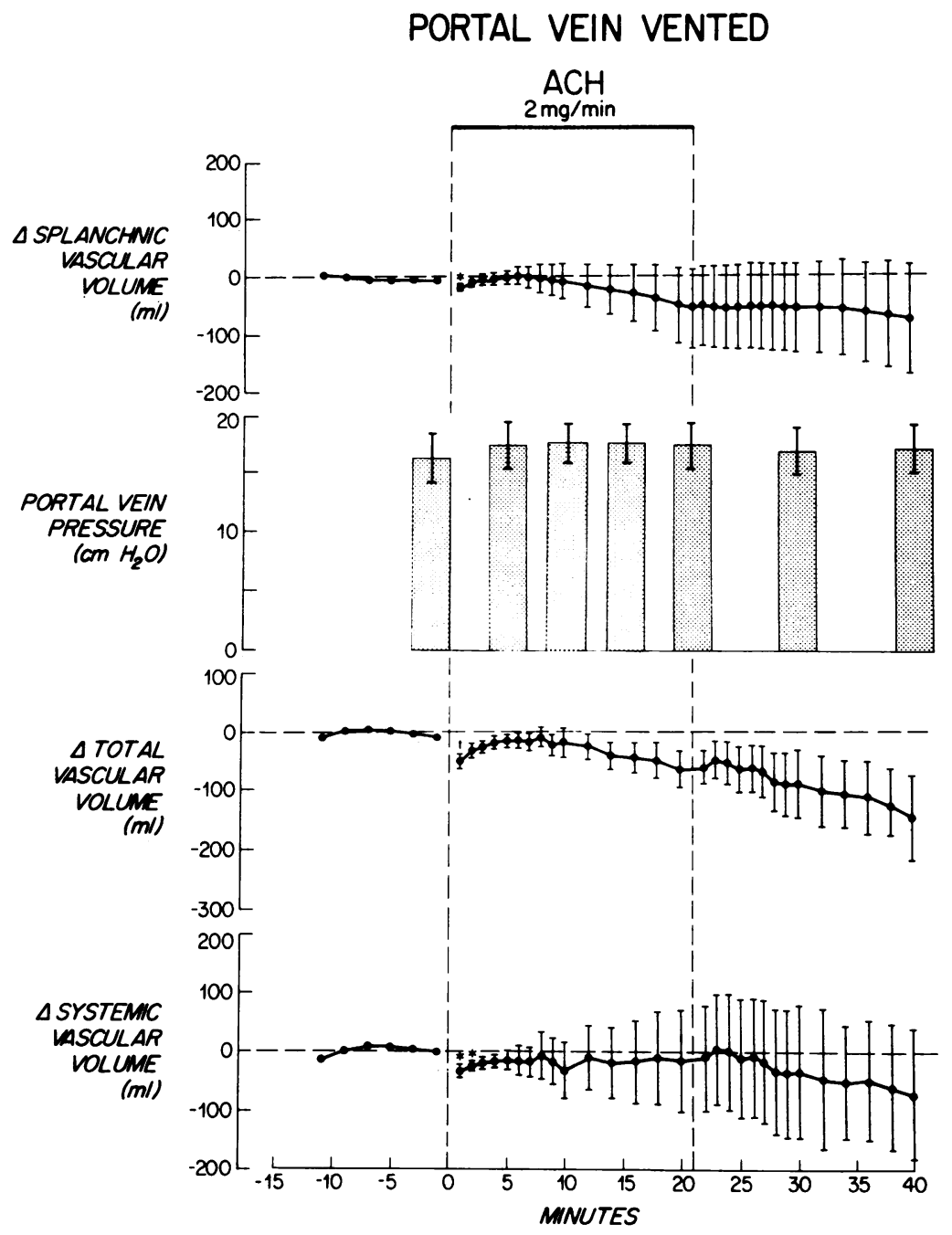

FIGURE 4 The effect of intraarterial acetylcholine (ACH) on splanchnic and systemic hemodynamics in seven animals in which the portal vein has been vented. See text for details. Note the lack of a significant change in splanchnic vascular volume, portal vein pressure, and total vascular volume. ${ }^{*} P<0.05,+P<0.01, n=7$. 


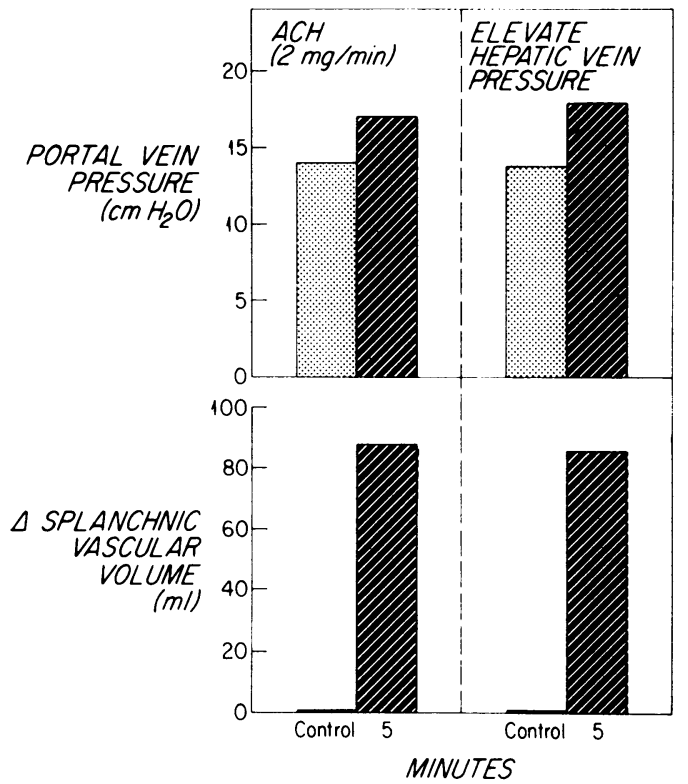

FIGURE 5 A comparison of the effects of acetylcholine $(\mathrm{ACH})$ and mechanical elevation of hepatic vein pressure on splanchnic vascular volume. Note the similarity in the increase in splanchnic vascular volume produced by elevating portal venous pressure to the same level with either intervention.

portal vein pressure of $3.4 \pm 2 \mathrm{~cm} \mathrm{H}_{2} \mathrm{O}$ from a control of $14.7 \pm 2 \mathrm{~cm} \mathrm{H}_{2} \mathrm{O}$ that was associated with a gain in splanchnic volume of $116 \pm 13 \mathrm{ml}$. After each of the above two interventions, there was a persistent gain in splanchnic vascular volume $(146 \pm 10 \mathrm{ml} 5 \mathrm{~min}$ after the acetylcholine infusions and $92 \pm 23 \mathrm{ml} 5 \mathrm{~min}$ after the return of hepatic vein pressure to control).

In three animals hepatic vein wedge pressures were measured intermittently during acetylcholine administration in order to determine the location within the hepatic vasculature of the effect of acetylcholine. As can be seen in the third and fourth panels of Fig. 6, hepatic vein wedge pressure was within $0.5 \mathrm{~cm} \mathrm{H}_{2} \mathrm{O}$ of portal pressure in the control periods. Furthermore, in response to acetylcholine both portal vein pressure and hepatic vein wedge pressure rose. Although portal pressure tended to be slightly greater than the hepatic vein wedge pressure, it was always within $1.2 \mathrm{~cm} \mathrm{H}_{2} \mathrm{O}$ of the latter. This is consistent with findings in the literature about the relationship of portal pressure to hepatic vein wedge pressure (13). In the other two animals, hepatic vein wedge pressure also rose in response to acetylcholine (from 10.8 to $16.5 \mathrm{~cm} \mathrm{H}_{2} \mathrm{O}$ and from 19.7 to $21.8 \mathrm{~cm} \mathrm{H}_{2} \mathrm{O}$ ) and was consistently within $1 \mathrm{~cm} \mathrm{H}_{2} \mathrm{O}$ of portal vein pressure.

Fig. 6 also demonstrates that the effect of acetylcholine on the splanchnic vasculature could be blocked by atropine. In two other animals, atropine blockade also abolished the response to acetylcholine observed during the first infusion. In each of three animals, two 5-min infusions of acetylcholine were administered in sequence. The second infusion exhibited the usual response to acetylcholine of increased transhepatic resistance and increased splanchnic vascular capacity. The gain in splanchnic vascular volume was 100,95 , and $70 \%$ of that observed during the first infusion, indicating little to no tachyphylaxis to repeated infusions of acetylcholine.

To investigate whether reflex adrenergic activity might account for the effect of acetylcholine on the splanchnic vasculature, this agent was infused in nine animals following alpha, beta, or combined alpha and beta adrenergic receptor blockade. The results of 13 infusions are shown in Table II. Splanchnic vascular capacity and transhepatic resistance increased to a similar or greater extent in response to acetylcholine following adrenergic blockade, indicating that the primary effect of acetylcholine is not mediated by adrenergic receptor stimulation.

The effect on total vascular capacity of vagal stimulation in five dogs can be seen in Fig. 7. After $11 \mathrm{~min}$ stable control, total vascular volume rapidly increased during vagal stimulation. At $10 \mathrm{~min}$ after the onset of vagal stimulation the gain in intravascular volume was $69 \pm 14 \mathrm{ml}(P<0.01)$. Summing up the changes in splanchnic outflow it appeared that the splanchnic corresponding volume changes were $155 \pm 58 \mathrm{ml}(P$ $<0.05)$. However, it was not possible to quantitate separately the specific change in splanchnic vascular volume since vagal stimulation also affects splanchnic arterial resistance (11), and arterial resistance changes may modify changes in splanchnic vascular capacity (14). Since in these experiments the primary, if not the sole effect of vagal stimulation is on the splanchnic organs, the major effect on capacity must have occurred in the splanchnic circulation. In two additional animals, following atropine blockade, there was no gain in total vascular volume with $10 \mathrm{~min}$ of vagal stimulation.

\section{DISCUSSION}

The present data demonstrate that acetylcholine administration is associated with a rapid and significant gain in splanchnic vascular volume. This increase in splanchnic vascular capacity is mediated by a direct effect. The primary site of action of acetylcholine is on the hepatic vasculature with little effect on the portal venous system per se. The effect on the hepatic vasculature is to elevate transhepatic resistance to portal blood flow, and this elevation of resistance appears to account for the observed gain in splanchnic vascular 


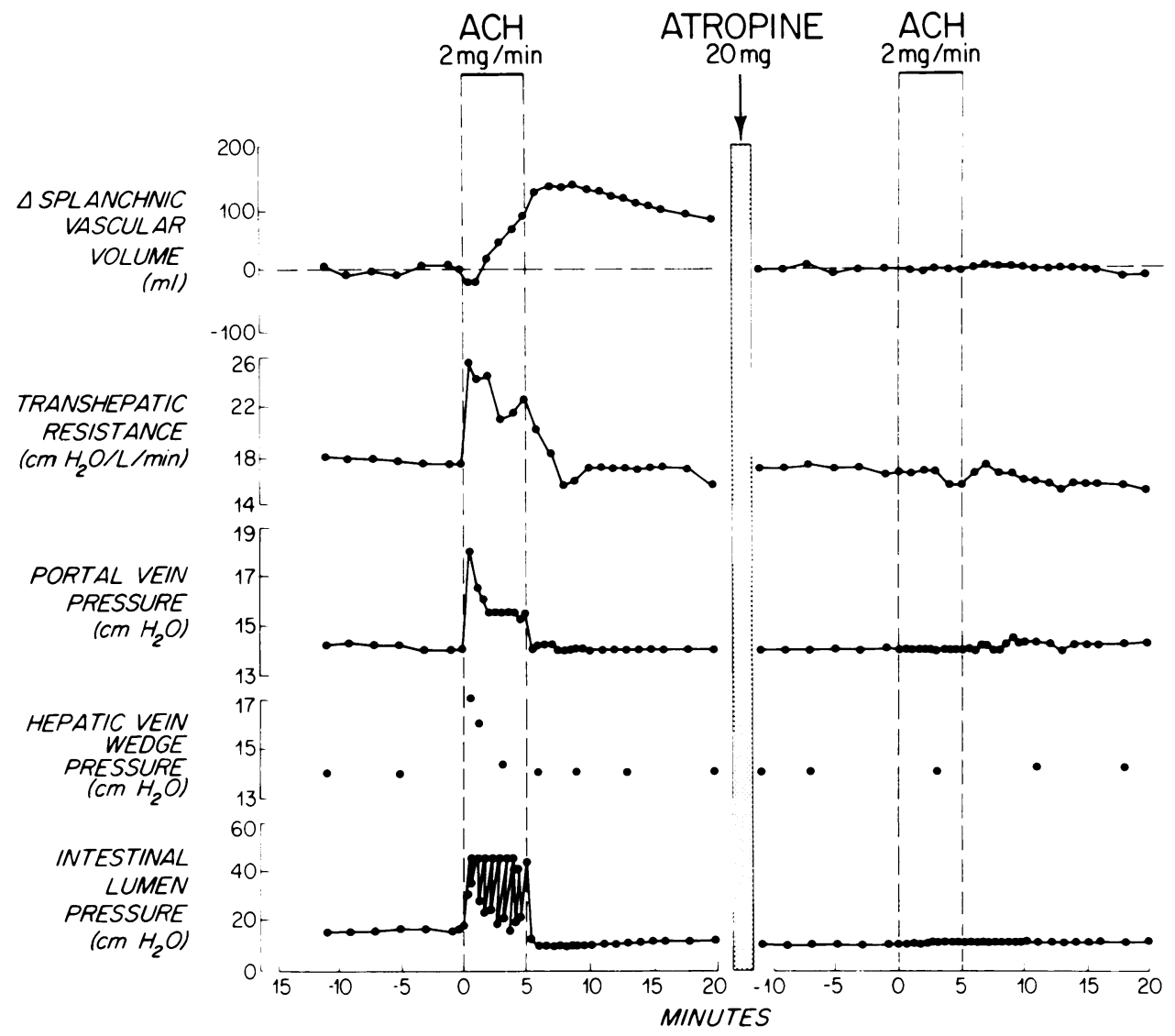

FIGURE 6 The effect of sequential intraarterial infusions of acetylcholine (ACH) in the same animals before and after the administration of $20 \mathrm{mg}$ of atropine to the 4-liter blood reservoir. Note that the administration of atropine abolished the hemodynamic and intestinal lumen pressure effects of acetylcholine. Note also that with the administration of acetylcholine before atropine blockade, hepatic vein wedge pressure rose in parallel with portal vein pressure and remained within $1.2 \mathrm{~cm} \mathrm{H}_{2} \mathrm{O}$ of the latter throughout the experiment.

volume. The gain in splanchnic capacity entirely accounts for the increase in total vascular volume observed in this study.

Redistribution of arterial blood flow from one area of the circulation to another can produce an increase in capacity in the area that receives the increase in arterial flow (14). In this study, arterial redistribution from the systemic to the splanchnic circulation or redistribution between the mesenteric and hepatic arterial systems could not have accounted for the observed gain in splanchnic vascular volume, because the increase in capacity occurred under conditions of separate perfusion of these systems. The majority of the increase in splanchnic vascular volume is located within sites other than the arterial system, since splanchnic vascular capacity increases independently of the direction of the change in mesenteric arterial resistance. Dilatation of the portal venous system could result in an increase in splanchnic vascular capacity, but in the animals with the portal vein vented proximal to the liver and portal pressure maintained nearly constant, splanchnic vascular volume did not increase. In fact, a small, insignificant decrease in splanchnic vascular volume was observed, which is consistent with slight venoconstriction of the portal venous system. Thus, the increase in splanchnic vascular volume observed in the intact animals with acetylcholine infusion appears likely to be due to an effect on the hepatic vasculature.

Transhepatic resistance to portal blood flow rises rapidly and remains substantially elevated during acetylcholine administration. Both the decrease in hepatic vein outflow and the increase in portal vein pressure contribute to this increase in transhepatic resistance. The data from the experiments in which hepatic vein pressure was elevated in order to increase portal vein 
TABLE II

Effect of 5-min Infusions of Acetylcholine (2 $\mathrm{mg} / \mathrm{min}$ ) following Adrenergic Receptor Blockade

\begin{tabular}{|c|c|c|c|c|c|c|c|c|c|}
\hline & \multicolumn{3}{|c|}{$\alpha$-Adrenergic blockade } & \multicolumn{3}{|c|}{$\beta$-Adrenergic blockade } & \multicolumn{3}{|c|}{$\alpha$ - and $\beta$-Adrenergic blockade } \\
\hline & \multirow{2}{*}{$\begin{array}{c}\Delta \text { Splanchnic } \\
\text { vascular } \\
\text { volume } \\
5 \mathrm{~min}\end{array}$} & \multicolumn{2}{|c|}{$\begin{array}{l}\text { Transhepatic } \\
\text { resistance }\end{array}$} & \multirow{2}{*}{$\begin{array}{c}\Delta \text { Splanchnic } \\
\text { vascular } \\
\text { volume } \\
5 \mathrm{~min}\end{array}$} & \multicolumn{2}{|c|}{$\begin{array}{l}\text { Transhepatic } \\
\text { resistance }\end{array}$} & \multirow{2}{*}{$\begin{array}{c}\Delta \text { Splanchnic } \\
\text { vascular } \\
\text { volume, } \\
5 \text { min }\end{array}$} & \multicolumn{2}{|c|}{$\begin{array}{l}\text { Transhepatic } \\
\text { resistance }\end{array}$} \\
\hline & & Control & $5 \mathrm{~min}$ & & Control & $5 \mathrm{~min}$ & & Control & $5 \mathrm{~min}$ \\
\hline & $m l$ & \multicolumn{2}{|c|}{$\mathrm{cm} \mathrm{H}_{2} \mathrm{O} /$ liter per min } & $m l$ & \multicolumn{2}{|c|}{$\mathrm{cm} \mathrm{H} \mathrm{H}_{2} \mathrm{O} /$ iter per min } & $m l$ & \multicolumn{2}{|c|}{$\mathrm{cm} \mathrm{H}_{2} \mathrm{O} /$ liter per min } \\
\hline Unblocked & 34 & 61.3 & 76.7 & & & & 34 & 61.3 & 76.7 \\
\hline Blocked & 147 & 43.8 & 97.5 & & & & 68 & 128 & 182 \\
\hline Unblocked & & & & 41.2 & 27.1 & 27.4 & 4.2 & 27.1 & 27.4 \\
\hline Blocked & & & & -3 & 50.8 & 61.8 & 13.3 & 50 & 70.6 \\
\hline Unblocked & 524 & 48.7 & 197 & & & & & & \\
\hline Blocked & 668 & 120 & 421 & & & & & & \\
\hline Unblocked & & & & 73 & 5.5 & 13.6 & 72.7 & 5.5 & 13.6 \\
\hline Blocked & & & & 133 & 13.1 & 32.9 & 203 & 17.9 & 52.8 \\
\hline Unblocked & & & & 139 & 22.7 & 59.1 & & & \\
\hline Blocked & & & & 163 & 135 & 172 & & & \\
\hline Unblocked & 39.7 & 30.8 & 32.8 & & & & 39.7 & 30.8 & 32.8 \\
\hline Blocked & 103 & 53.6 & 73.1 & & & & 156 & 62.5 & 118 \\
\hline Unblocked & & & & 66 & 12 & 13.8 & & & \\
\hline Blocked & & & & 74 & 17.2 & 25 & & & \\
\hline Unblocked & & & & 54 & 39.5 & 45.0 & & & \\
\hline Blocked & & & & 119 & 87.4 & 106 & & & \\
\hline Unblocked & 3 & 11.7 & 16.9 & & & & & & \\
\hline Blocked & 32 & 17.0 & 23.0 & & & & & & \\
\hline Mean unblocked & $150 \pm 125$ & $38 \pm 11$ & $81 \pm 41$ & $62 \pm 18$ & $20 \pm 5$ & $30 \pm 8$ & $38 \pm 20$ & $31 \pm 12$ & $38 \pm 14$ \\
\hline Mean blocked & $238 \pm 145$ & $59 \pm 22$ & $153 \pm 90$ & $63 \pm 30$ & $57 \pm 16$ & $69 \pm 20$ & $110 \pm 43$ & $65 \pm 23$ & $106 \pm 29$ \\
\hline
\end{tabular}

Each horizontal row of paired numbers represents the data from one animal. Note that directionally similar increases in splanchnic vascular volume and in transhepatic resistance were produced by acetylcholine both before and after adrenergic receptor blockade. $n=9$.

pressure to the same level that had occurred with prior acetylcholine administration indicate that the increase in transhepatic resistance is an important mechanism whereby acetylcholine increases vascular capacity.

Acetylcholine exerts its effect on the postsinusoidal vasculature in the hepatic venules and veins. This is demonstrated by the data from the experiments in which portal vein and hepatic vein wedge pressures were monitored. In the liver, there is communication among the sinusoids that allows blood flow to occur into and out of the sinusoids proximal to the wedged hepatic vein (15). Hepatic vein wedge pressure determinations measure sinusoidal pressure (13). Because portal vein pressure and hepatic vein wedge pressure closely approximated each other in these experiments, and both increased in response to acetylcholine, the site of the constriction must be primarily postsinusoidal. Anatomic evidence of the existence of sphincters in the hepatic venules and veins of the dog has been demonstrated $(16,17)$. The walls of the hepatic venules are invested with thick smooth muscle that is predominantly longitudinally oriented. At the junction of the hepatic venules with the hepatic veins, this muscular wall thickens and some of the fibers are circumferential. Microscopic sections after stimulation with acetylcholine have demonstrated constriction of the vessels in these areas (18). This anatomic evidence, combined with the present physiologic data, explains how acetylcholine, which venoconstricts isolated veins (11), can increase splanchnic vascular capacity.

Constriction of the postsinusoidal sphincter most likely occurs through a direct effect of acetylcholine. This agent was administered into the splanchnic arteries to minimize the possibility that the release of a circulating hormone from the adrenals, kidneys, or other organs in response to acetylcholine could be solely responsible for the observed effects. The increase in portal pressure and transhepatic resistance 


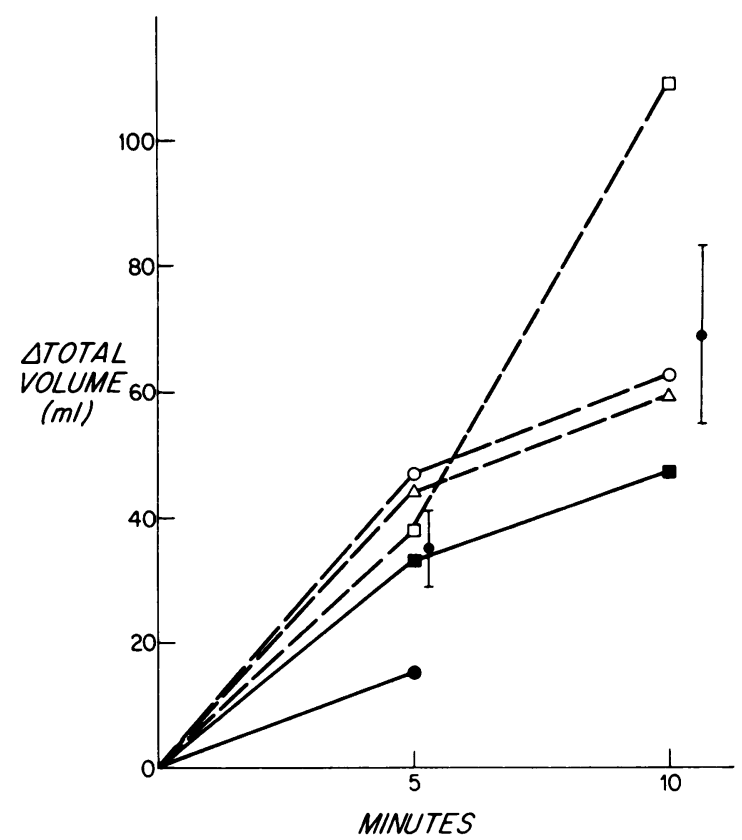

Figure 7 The effect of stimulation of the distal ends of the sectioned cervical vagi on total vascular volume in each of five animals following $11 \mathrm{~min}$ of stable control. For these experiments, the central venous pressure was set at $8 \mathrm{~cm} \mathrm{H}_{2} \mathrm{O}$. The means at 5 and $10 \mathrm{~min}$ of vagal stimulation were both significant $(P<0.05)$.

occurred within $1 \mathrm{~min}$ of the onset of acetylcholine administration. These effects could not be caused by recirculation of blood containing a systemically released hormone, considering the circulation times involved, the isolation of hepatic venous outflow during blood flow determinations, and the volume of the blood reservoir. The presence of a directionally similar effect of acetylcholine on splanchnic vascular capacity following adrenergic receptor blockade indicates that the above effects of acetylcholine are not dependent upon an intact adrenergic system. Furthermore, atropine abolished the increase in intestinal activity, the increase in transhepatic resistance, and the gain in splanchnic vascular volume associated with acetylcholine administration.

Although not significant, there was a tendency for the gain in splanchnic vascular capacity to slightly exceed that of total capacity. Shunting of blood from the higher pressure portal system to the central venous circulation could be a mechanism for this difference, but in the animals in which all visible collaterals were ligated, there was no significant difference in response to acetylcholine. The small, but statistically insignificant, systemic venoconstrictor effect of acetylcholine noted in the eviscerated animals could explain the tendency for the gain in splanchnic capacity to exceed that of total capacity.
The persistent elevation in splanchnic vascular volume in some experiments following the termination of acetylcholine infusion may, in part, have been secondary to transudation of fluid into the interstitium because of the increased capillary pressure. The data from the experiments in which hepatic venous and portal pressure were mechanically elevated support this concept, because splanchnic volume did not return promptly to control following return of portal pressure to its initial level. Whatever the amount, any increase in interstitial fluid would result in volume being retained in the splanchnic viscera that would be unavailable to the central circulation.

It is likely that the mechanism whereby acetylcholine increases splanchnic vascular volume has relevance in the intact organism. Anatomically, acetylcholine esterase staining techniques have demonstrated parasympathetic fibers and ganglia in the walls of portal veins, central veins, and hepatic veins as they enter the vena cava (7). The hepatic artery receives only sympathetic innervation (19). Furthermore, as shown in Fig. 7, with electrical stimulation of the vagus nerve, an increase in total vascular volume occurred.

Anatomically, the hepatic veins of other species have been shown to contain smooth muscle, and a response to acetylcholine has been demonstrated. Tyler (20) found that the hepatic but not the portal veins of the turtle had spirally arranged smooth muscle in their walls. Hepatic venous outflow decreases in response to acetylcholine infusion in the isolated perfused turtle liver (21). Deysach (18) noted swelling of the liver and restriction of outflow in the isolated, perfused livers of rabbits, cats, and vevet monkeys in response to acetylcholine. Deysach (18) also observed that the hepatic veins and their branches in these species were muscular and thick-walled. On microscopic section, following acetylcholine administration, constricted areas of the hepatic veins were observed.

Anatomical evidence for a postsinusoidal sphincter has been shown in man. Popper (22) described the junction of central veins with hepatic venules as being "funnel-like." Elias and Popper (23) noted that thin-walled hepatic venules in the human constricted on entering thick-walled vessels. In neoprene casts of the hepatic venous system in man, the junctions of central venules and hepatic veins were sometimes retracted (24). Since these junctions were numerous, Gibson (24) concluded that junctional constriction was probably the "chief venous sphincter mechanism in the human liver." Hepatic veins in man have been shown to have a longitudinally oriented smooth muscle in their walls $(25,26)$.

Thus, anatomically, it appears that man is capable of the same response to acetylcholine observed in our experiments. The physiologic documentation of this 
effect remains to be demonstrated in the human. The data from the present experiments suggest that there is a cholinergically mediated increase in transhepatic resistance to portal blood flow resulting in a sequestration of blood volume in the splanchnic vasculature that would decrease venous return to the heart.

\section{ACKNOWLEDGMENTS}

This study was supported in part by a grant from The Educational Foundation of America, Inc., and by a grant from The Bird Companies Charitable Foundation, Inc., and U. S. Public Health Service National Institutes of Health 1-R01-HL 18657.

\section{REFERENCES}

1. Shepherd, J. T., and P. M. Vanhoutte. 1978. Role of the venous system in circulatory control. Mayo Clin. Proc. 53: $247-255$.

2. Levy, M. N., R. I. Lipman, and H. Zieske. 1966. Vagus nerves and baroreceptor control of ventricular performance. Circ. Res. 18: 101-106.

3. Sarnoff, S. J., S. K. Brockman, J. P. Gilmore, R. J. Linden, and J. H. Mitchell. 1960. Regulation of ventricular contraction: influence of cardiac sympathetic and vagal nerve stimulation on atrial and ventricular dynamics. Circ. Res. 8: $1108-1122$.

4. Tansy, M. F., R. L. Mackowiak, and M. H. F. Friedman. 1968. Influence of stimulation of the central end of the vagus nerve on gastric secretion. Surg. Gynecol. Obstet. 127: 259-269.

5. Govaerts, J. P., and R. Kiekens. 1968. Role of vagal innervation on pancreatic section. Surgery. 63: 942-947.

6. Kuntz, A. 1953. The Autonomic Nervous System. Lea \& Febiger, Philadelphia, Pa. 210-211.

7. Sutherland, S. D. 1964. An evaluation of cholinesterase techniques in the study of the intrinsic innervation of the liver. J. Anat. (Lond.). 98: 321-326.

8. Horvath, S. M., T. Kelly, G. E. Folk, Jr., and B. K. Hutt. 1957. Measurement of blood volumes in the splanchnic bed of the dog. Am. J. Physiol. 189: 573-575.

9. Mall, F. P. 1892. Er einfluss des systems der vena portae auf die vertheilung der blutes. Arch. Physiol. (Lepsiz). 16: $409-453$.

10. Rutlen, D. L., E. W. Supple, and W. J. Powell, Jr. 1981.
$\beta$-Adrenergic regulation of total systemic intravascular volume in the dog. Circ. Res. 48: 112-120.

11. Shepherd, J. T., and P. M. Vanhoutte. 1975. Veins and Their Control. W. B. Saunders Company, Philadelphia, Pa. 32-36.

12. Mosteller, F., and R. E. K. Rourke. 1973. Study Statistics: Nonparametrics and Order Statistics. Addison-Wesley Publishing Co., Inc., Reading, Mass., 89-102.

13. Friedman, E. W., and R. S. Weiner. 1951. Estimation of hepatic sinusoid pressure by means of venous catheters and estimation of portal pressure by hepatic vein catherization. Am. J. Physiol. 165: 527-531.

14. Caldini, P., S. Permutt, J. A. Waddell, and R. L. Riley. 1974. Effect of epinephrine on pressure, flow, and volume relationships in the systemic circulation of dogs. Circ. Res. 34: 606-623.

15. Price, J. B., Jr., P. A. McFate, and R. F. Shaw. 1964. Dynamics of blood flow through the normal canine liver. Surgery. 56: 1109-1120.

16. Arey, L. B., and J. P. Simonds. 1920. The relation of the smooth muscle in the hepatic veins to shock phenomena. Anat. Rec. 18: 219. (Abstr.)

17. Walker, W. F., J. S. MacDonald, and C. Pickard. 1960. Hepatic vein sphincter mechanism in the dog. $B r . J$. Surg. 48: 218-220.

18. Deysach, L. J. 1941. The nature and location of the "sphincter mechanism" in the liver as determined by drug actions and vascular injections. Am. J. Physiol. 132: 713-724.

19. Alexander, W. F. 1940. The innervation of the biliary system. J. Comp. Neurol. 72: 357-370.

20. Tyler, F. H. 1941. A note on the microstructure of the turtle's liver. Anat. Rec. 79: 541-545.

21. Snyder, C. D. 1942. Some vascular responses within liver and their interpretation. Rev. Gastroenterol. Mex. 9: 230-235.

22. Popper, H. 1931. Uber drossel vorrichtugen an lebervenen. Klin. Wochenschr. 10: 2129-2131.

23. Elias, H., and H. Popper. 1955. Venous distribution in livers. Arch. Pathol. Lab. Med. 59: 332-340.

24. Gibson, J. B. 1959. The hepatic veins in man and their sphincter mechanisms. J. Anat. (Lond.) 93: 368-379.

25. Elias, H., and A. Feller. 1926. Stauungstypen bei Kreislaufsstorungen. J. Springer, Berlin.

26. Miyake, M. 1929. Vergleichende Studien über den feinen Bau der Pfortader und Lebervenen. Arb. Med. Univ. Okayama. 1: 166-172. 